\title{
Psychological Research of the Ability to Foreign Languages Acquisition
}

\author{
GANNA KOZLOVSKA ${ }^{1}$, ANATOLII FURMAN ${ }^{2}$, NATALIA KOLESNICHENKO ${ }^{3}$, \\ NADIIA KHARCHENKO ${ }^{4}$, KATERYNA HALATSYN ${ }^{5}$, NATALIA MATORINA ${ }^{6}$ \\ ${ }^{1}$ Foreign Languages Department, SUMY STATE UNIVERSITY, UKRAINE. \\ ${ }^{2}$ Theory and Methods of Practical Psychology Department, SOUTH UKRAINIAN NATIONAL PEDAGOGICAL \\ UNIVERSITY NAMED K.D. USHYNSKYI, UKRAINE. E-mail: anna_kozlovska@ukr.net \\ ${ }^{3}$ German Language Philology Department, ODESSA I. I. MECHNIKOV NATIONAL UNIVERSITY, UKRAINE. \\ ${ }^{4}$ Psychology Department, PAVEL TYCHYNA UMAN STATE PEDAGOGICAL UNIVERSITY, UKRAINE. \\ ${ }^{5}$ English for Engineering №2 Department, NATIONAL TECHNICAL UNIVERSITY OF UKRAINE “IGOR SIKORSKY KYIV \\ POLYTECHNIC INSTITUTE", UKRAINE. \\ ${ }^{6}$ Germanic and Slavonic Linguistics Department, DONBAS STATE TEACHERS' TRAINING UNIVERSITY, UKRAINE.
}

\begin{abstract}
Along with psychological approaches and concepts of teaching foreign languages, concepts of mastering a foreign language, built on the ideas of appropriation and interpretation of a foreign language linguistic experience, have spread in psychological science. While not being opposed to theories of teaching foreign languages, these concepts and approaches, however, have some differences from them, which also require analysis and interpretation. To avoid misunderstandings in the use of the most general concepts from the field of psychology of mastering foreign languages, in their study the authors clarify them, guided by the literary materials that make up its scientific paradigm. The authors analysed the use of non-standard techniques to facilitate the acquisition of foreign languages.

In their research, the authors tested the hypothesis that in the conditions of personality-oriented dialogical teaching of a foreign language, personal characteristics that complicate foreign language communication are significantly optimised. As a result of the experimental work, the hypothesis was confirmed; still, in an even more strengthened form: the significant connection between the motivation of learning and the level of development of abilities for languages is fundamentally destroyed. In other words, in the conditions of studentcentred learning, insufficient development of potential language abilities ceases to be a factor that negatively affects the motivation of learning.
\end{abstract}

Keywords: ability, bilingual first language acquisition, foreign language, student

JEL Classification: 121, 129, Z13

Received: 17 March 2021

Accepted: 2 April 2021 


\section{Introduction.}

Mastering a foreign language is not necessarily due to educational practice, not limited only by the framework of the educational process. For this reason, not all the provisions of psychological theories of mastering a foreign language are directly extrapolated to the situation of teaching foreign languages. In this regard, psychological theories of acquiring a foreign language are of interest to us only in that part of them that directly correlates with the process and results of learning a foreign language. The earliest in time of creation is the concept of the Georgian psychologist Alkhazishvili (1988). Formulating the starting points of his concept, he claims that teaching foreign oral speech, which is determined by the very specifics of this process, has low efficiency. The main reason for this is the traditional formation of methods of teaching foreign languages based on linguistics and inconsistent reliance on data from psychology, especially in the development of specific learning systems. At the same time, the author proposes his own approach, which is based on taking into account the psychological laws of teaching foreign oral speech.

The works of other scientists carried out in the mainstream of the same scientific psychological school, consider the broader context of language acquisition and proficiency in real bilingualism (Imedadze, 1979; Hulk \& Müller, 2000). that mastering a second language in this situation is somewhat different from the position of acquiring a foreign language properly. The conclusions proposed based on their experimental psychological constructions are essential for the psychological theory and practice of teaching foreign languages. First of all, we are talking about interaction, clash of languages - native and second (foreign) - in the course of learning and anticipating the nature of this collision, managing it from the perspective of a foreign language teacher, which is why psychological studies of the ability to master foreign languages are relevant today.

\section{The specifics of the process of mastering foreign languages.}

To avoid misunderstandings in the use of the most general concepts from the field of psychology of mastering foreign languages is advisable to clarify them, guided by the literary materials that make up its scientific paradigm.

First of all, you need to pay attention to the concepts associated with the process and result of language learning. Such, for example, as "language proficiency", "language knowledge", "language learning", "language acquisition".

Language acquisition is the process by which a person acquires the ability to perceive and understand language (in other words, acquires the ability to understand and comprehend language), as well as to produce and use words and sentences for communication.

Language proficiency is the completion of the assimilation process, its result. From ignorance of even elementary expressions in this language, a person eventually comes to the fact that he uses a new means of communication, without even noticing the total (Guryanova et al., 2020).

There is a significant distance between the complete inability to use a foreign language and mastering it, which involves a considerable investment of time and energy. This distance is the process of developing foreign language speakers.

Learning a language is a process of acquiring knowledge about the corresponding language. In contrast, the concept of language acquisition does not imply a distinction between the concepts of "language knowledge" and "language proficiency". In the above definitions, two more concepts were actively used, which are also essential to distinguish and adequately use. This is speech and language, phenomena that are inextricably linked with each other but are different.

Language is a system of signs that serve as a means of human communication. Speech, on the other hand, is a process of communication that involves the generation and understanding of statements based on a particular language. Language is common to all people; speech is specific, individual and unique. For this reason, the concepts of "possession", "study", "assimilation", "knowledge" are not combined with the concept of "speech". The language is learned; it is mastered; 
it is studied. Speech develops, improves, is generated, is broken. Speech and language are of interest not only to psychologists but also to representatives of other sciences. And in each of them, due to the specifics of the formation and functioning, the attention of researchers is focused on different aspects and interrelationships. For example, linguists are interested in the relationship of language with such a mental process as thinking. In psychology, the emphasis is on the connection between speech and thought, since these are ideal phenomena in which the human psyche is manifested. Naturally, the existing differences are a possible reason for misunderstandings that arise during discussions between specialists of different profiles.

Language acquisition usually refers to the acquisition of a first language, i.e. the acquisition of a mother tongue by infants, whether spoken or sign language due to pre-speech deafness, although this may also apply to bilingual first language acquisition (BFLA), which means the simultaneous acquisition of two mother tongues by a child (Hulk \& Müller, 2000; Paradis \& Genesee, 1996; Serratrice et al., 2004). It differs from the acquisition of a second language, which concerns the acquisition (by both children and adults) of additional languages. There are two types of it - pure and mixed. If two languages in human consciousness exist independently of each other, then this is pure bilingualism; in the absence of this condition, bilingualism is called mixed. Obviously, such an understanding of pure bilingualism presupposes full proficiency in both languages. In this case, such well-known psychological phenomena as the transfer of speech skills or their interference are excluded. In the first case, we are talking about the positive influence of a previously formed skill (action) on the mastery of a new one, which proceeds faster and easier than mastering the previous one. In the second, about the interaction of two or more processes (actions), in which there is a violation or difficulty in the implementation of at least one of them. With mixed bilingualism, transference and interference are almost inevitable. The purposeful formation of pure bilingualism in a family environment is not excluded. When teaching a foreign language, it is impossible to remove the native language from the student's consciousness, and therefore, it is impossible to form pure bilingualism.

The process of language acquisition consists of several components (Fig. 1).

Language acquisition is one of the most characteristic features of a person (Kosslyn \& Osherson, 1996; Friederici, 2011).

\section{Non-standard techniques to facilitate the acquisition of foreign languages.}

To reduce the stressfulness of the educational process, and to avoid the need to memorise foreign words, new "exotic" teaching methods and techniques are needed.

These include, for example, hypnopedia as teaching a foreign language in natural sleep conditions. The effect turned out to be practically zero, and therefore the idea arose to use hypnosis for this purpose. After getting acquainted with the educational material (most often - texts, words), students are immersed in a hypnotic sleep and in this state, they perceive the material again. The general positive suggestion is sometimes practised as well. Indeed, the tension is relieved, and the strength of memorisation, as the authors of the "novelty" assert, is not lower than under ordinary learning conditions. However, this is unlikely to work, since the material being memorised is reproduced better if the reproduction is carried out in the same conditions in which it was memorised.

Suggestopedia, authored by the Bulgarian physician G. Lozanov in the 1950s, is, in principle, somewhat similar to hypnopedia (Lozanov, 1971, 1973; Bancroft, 1976). Elements of magic, suggestions are always attractive and reassuring, increase confidence in success (placebo effect). By reducing anxiety, the effectiveness of memorisation increases. It is no coincidence that suggestionstopedia served as a kind of basis for the emergence of an intensive direction in teaching foreign languages. 
Figure 1. The process of language acquisition

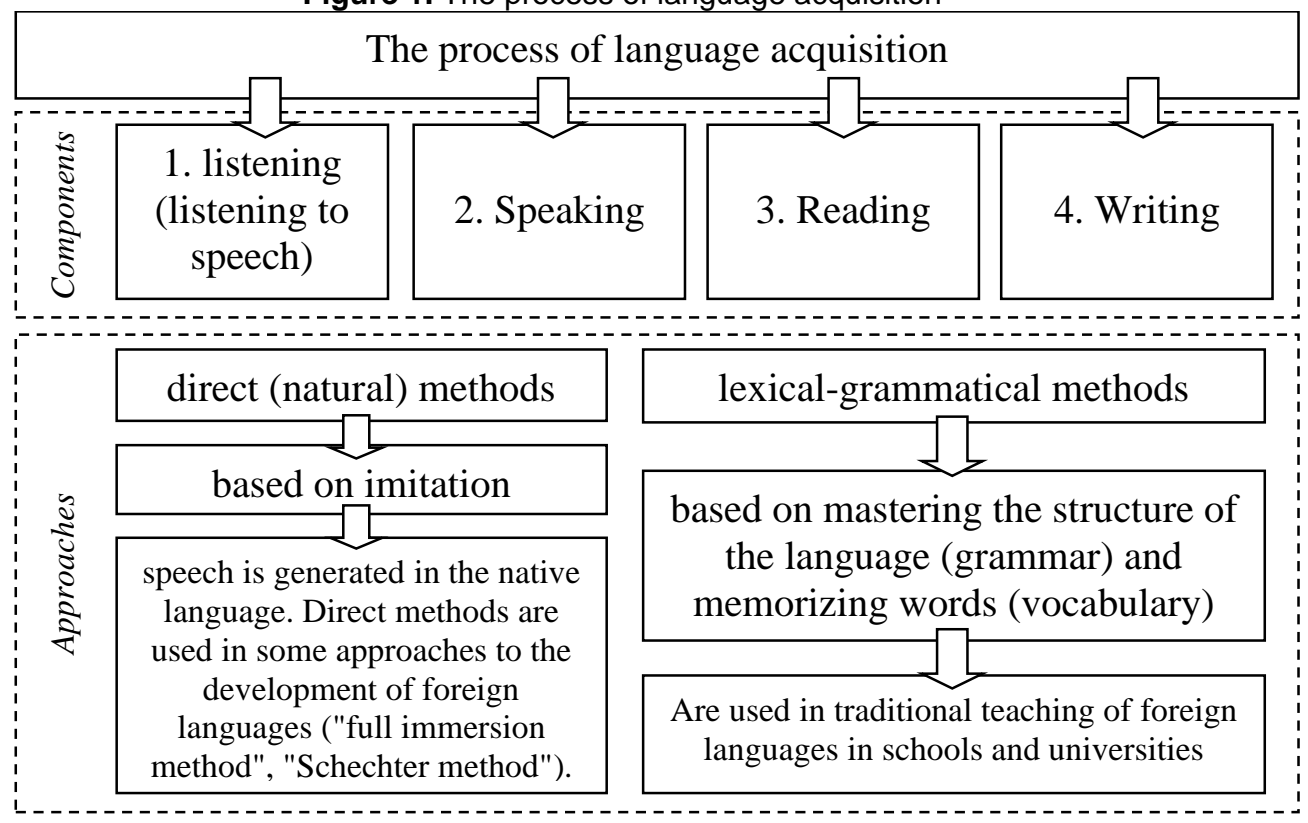

The method of intensive teaching of a foreign language - the authors, proceed from an utterly reasonable position that a person is not always aware of his capabilities or ways of their implementation (Kitaygorodskaya, 1986). When a vital need arises and the availability of suitable conditions, these opportunities can open up. This requires personally significant goals that mobilise personal resources. In other words, under the activation of personality capabilities is understood; first of all, an increase in motivation for learning. The success of the process of language acquisition primarily depends on the student's activity, and such motivational variables determine activity as the level of achievement planned by the individual in mastering the language, the value of achieving success and its expectation, the time and energy spent on achieving goals, the awareness of real achievements, the adequacy of the subjectively felt success real.

Neurolinguistic programming (NLP) languages can only be used to a very limited extent in teaching (Ahmadian, 2018). So, even knowing which representational system is the leading one for each student of the group or class member, one can only make it more developed, especially with regard to audials, who, as a rule, do not use in their entirety their advantages in mastering a foreign language. Besides, the dominance of any one representational system is observed, according to one of the authors of NLP, in 7-8 students out of 30. By the way, a similar ratio is mentioned in the types of memory, visual, auditory, motor and well-known from the course of general mixed psychology, which allows us to consider them as identical phenomena.

Ilona Davydova's methodology, which is based on the idea that listening to phrases in English (American version), accompanied by a translation into Russian, will provide an opportunity for their understanding and use in real communication. The sets of phrases were combined thematically: 1) In the city; 2) Meeting a person; 3) At the party; 4) Apartment 5) Love; 6) At the social offices; 7) Shopping 8) At the doctor's office; 9) Important occasions in life. Each phrase was pronounced first in English (very likely by the author of the technique), then its Russian equivalent followed, and the third time it was pronounced by a native speaker. There was a certain meaning in such a sequence since due to the lack of formation of a foreign language phonemic hearing, it is easier to perceive a phrase in an unfamiliar language if it is not pronounced by a native speaker. The selected phrases are undoubtedly useful, as they represent typical variants of the statements (or questions) in the specified situations. Unfortunately, it is hardly possible to get by with this set in real communication, if you did not master the language at the university or in some courses firstly. The grammatical minimum, which was contained in the instructions for the method, was too short of understanding what the structure of an English phrase is. Also, remembering it without knowing the lexical units of 
which it consists is extremely difficult. But it is precisely here that the central element of the "technique" is hidden, which ensured its popularity - the material is intentionally memorised and does not need to, since it is recorded on a magnetic tape with such a specific frequency that it immediately enters the listener's subconscious, bypassing the level of consciousness. The task facing the student is straightforward - you turn on the audio recording and just listen to the proposed material, which is recorded in memory, like on a magnetic tape. Pirated copies of tape recordings, it was emphasised in the hoax instructions, are deprived of this dignity, since during the re-recording that particular frequency is lost, which ensures the material gets directly into the subconscious.

And finally, one more relatively new methodology "Intellect" is focused on the visual representation system of the student. It is based on, as stated in the "methodological development", the phenomenon of "hypermnesia" (over-memorisation), arising in the process of applying the suggestive method of teaching, in which information is assimilated by a person, bypassing consciousness. When using this method, vocabulary training material with the help of a videotape recorder "is presented to the learner with a high frequency in the sub-sensory (unconscious) range of perception, and the learning process takes place at the level of unconscious mental activity." In other words, a person is promised that he, resting for a couple of hours in front of a TV screen, without stress, and in just 70 hours, will learn about 4000 words. The use of scientific terms, the magic of the "suggestive method", the ability to avoid stress ultimately provide the Barnum effect (Beins, 2010; Rosen, 2015), which manifests itself in this case in a person's tendency to accept at face value information presented under a scientific, magical or ritual sauce.

It should be noted that the technique is quite effective since along with the ritual ("test of the first wave, the test of the third wave") and suggestive (subconscious perception, lasting 15 minutes), it offers the most common work on fully conscious memorisation of words. After all, after the so-called suggestionological part, for 15 minutes on the screen at an average pace, foreign language words pronounced by the speaker are presented; another 15 minutes are allotted for the conscious memorisation of the same words printed on the "control cards" of this lesson. Each lesson begins with reviewing and reviewing the previous checklists, and ends with filling out the progress monitoring diary. It is interesting that a person hypnotised by the ritual-magic component of this technique is convinced that he does not "cram" foreign words. But if this component is removed, then, perhaps, he will hardly want to continue learning, since the process will immediately become similar to the usual conscious and voluntary memorisation, contemptuously called cramming by the authors of such exotic novelties themselves.

Recent advances in functional neuroimaging technologies have made it possible to understand better how language acquisition is manifested physically in the brain. Language acquisition almost always occurs in children during a period of rapid brain volume. At this stage of development, a child has many more neural connections than he or she in adulthood, which makes the child more able to learn something new for him or her as an adult (Newport, 1990; Steve, 1993).

Thus, the purpose of the experimental part is to test the hypothesis that in the conditions of personality-oriented dialogical teaching of a foreign language, personal characteristics that complicate foreign language communication are significantly optimised.

\section{Methodology: Psychological mechanisms of interaction of motivation and abilities of students in foreign language acquisition.}

As the analysis of the literature has shown, there are various methods and tools to improve the ability of foreign languages acquisition, one of which is the relationship between motivation and abilities (Tkachenko et al., 2019; Prokopenko et al., 2020). The authors conducted an experiment in which, in specially created conditions for dialogical learning and psychological preparation, they revealed the influence of motivation and skills on the effectiveness of foreign languages acquisition. The research algorithm looked like this (Fig. 2).

The data were evaluated on a 5-point scale using an integrated method. 
The diagnostic study involved 272 students from 5 universities (Cherkasy State Technological University, Mariupol State University, Pavel Tychyna Uman State Pedagogical University, South Ukrainian National Pedagogical University named K.D. Ushynsky, Sumy State University).

\section{Analysis of results.}

The study of the motives of mastering a foreign language in conjunction with the general communicative attitudes of students showed that the ratio of internal (professional, creative, cognitive, communicative and emotional-value motives) and external (pragmatic, ambition, duty) motives in the student motivation system is different depending on the dominant in their communication communicative setting (Fig. 3).

Figure 2. Algorithm for conducting an empirical study of the influence of psychological mechanisms of interaction of motivation and abilities of students in teaching foreign languages

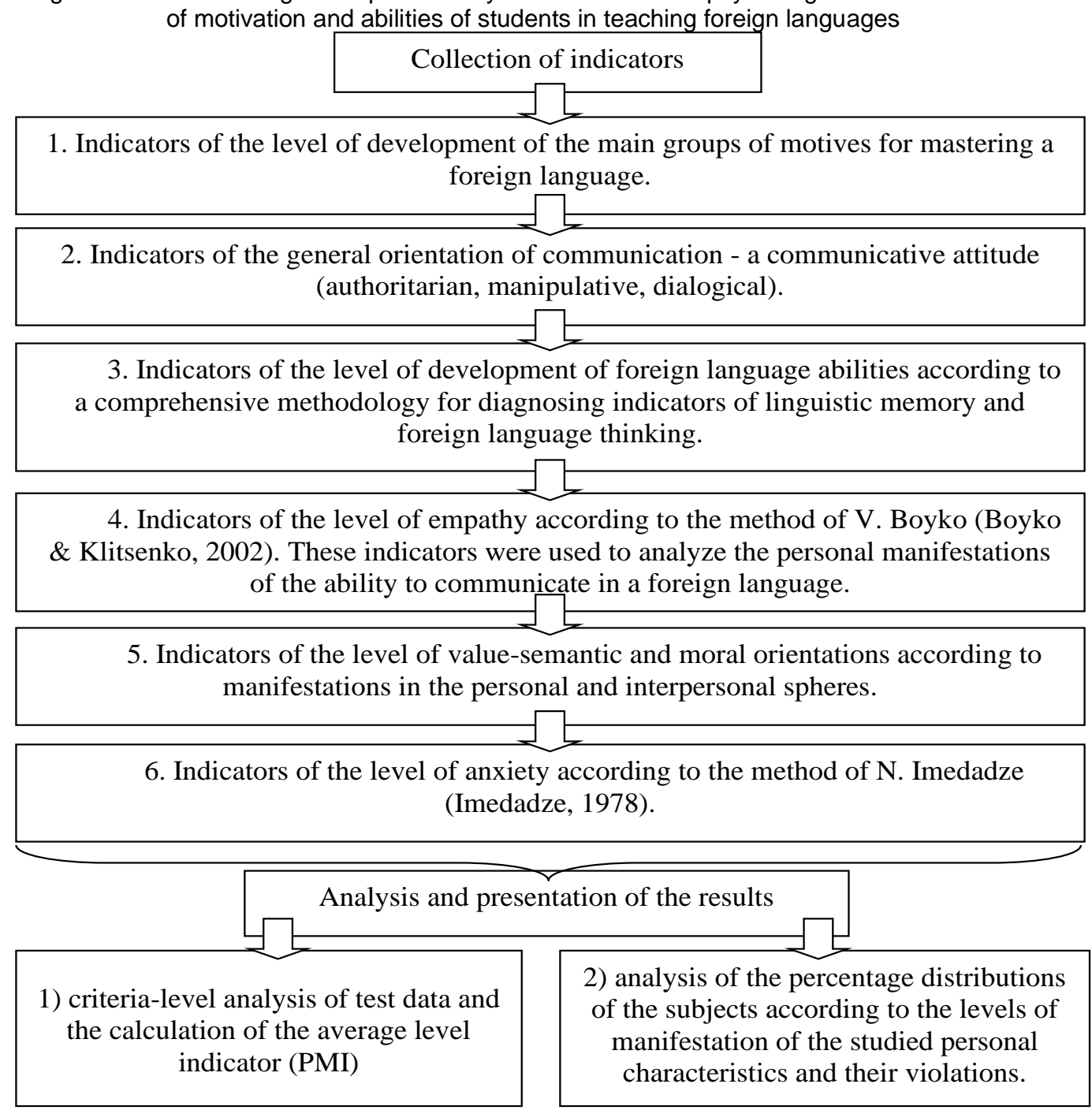

The data presented in the diagram show that among students with a predominant dialogical attitude of communication, internal motives clearly dominate in the process of mastering a foreign language (the average indicator of their severity for four types of motives is 4.0), and external motives act less often (the average indicator for three types of motives is a score of 2.7). In students with authoritarian communicative attitudes, intrinsic motivation is much less pronounced, and extrinsic motivation is much stronger, and both types of motivation are equally significant in their learning activities. These facts confirm the assumption that personality-oriented, dialogical foreign language communication in the process of teaching foreign languages is an important condition and 
an essential factor for optimal motivation for mastering a foreign language and foreign-language speech activity.

Figure 3. Analysis of the relationship between motives and the type of communicative attitude

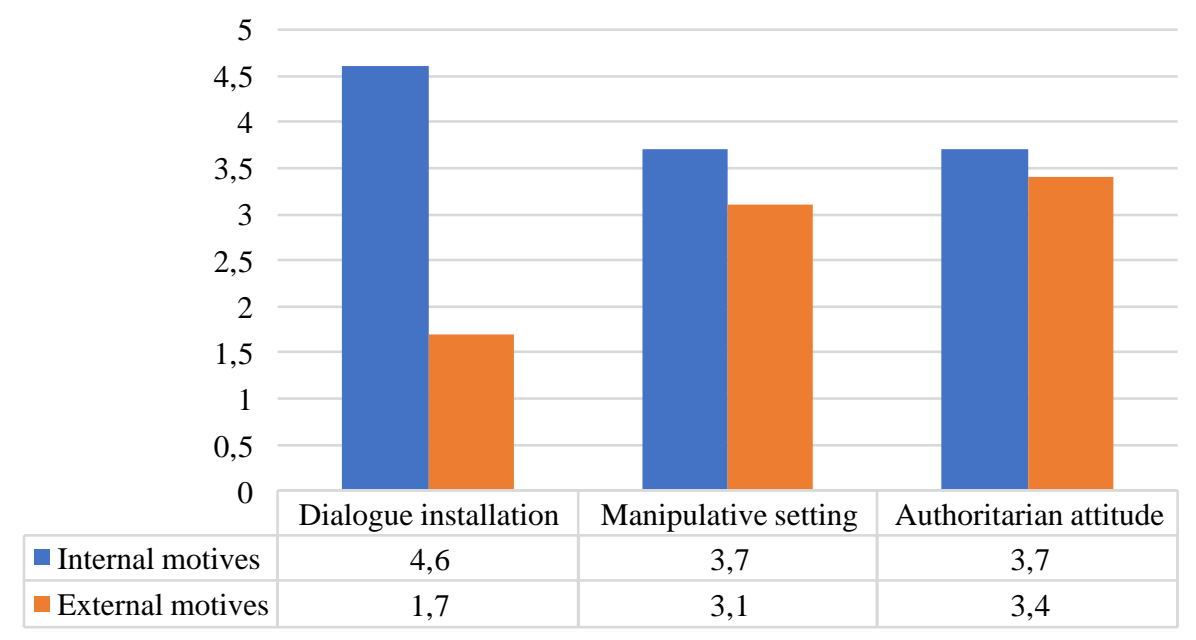

Table 1 shows comparative data on diagnostics of motivation and abilities of students, which were divided into 2 groups (A-control, B - experimental) at the diagnostic (before) and control (after) stages of the study. All indicators are expressed on a 5-point scale.

Table 1. Diagnostic data of students' motivation and abilities based on the results of the formative experiment

\begin{tabular}{|ll|c|c|c|c|}
\hline \multirow{2}{*}{ Indicators of motivation and ability } & \multicolumn{2}{c|}{ Group A } & \multicolumn{2}{c|}{ Group B } \\
\cline { 2 - 6 } & Before & After & Before & After \\
\hline 1. & Professional and creative & 3,5 & 4,2 & 3,4 & 3,5 \\
\hline 2. & Cognitive and educational & 3,5 & 4,4 & 3,5 & 3,6 \\
\hline 3. Intellectual and developmental & 3,4 & 4,6 & 3,4 & 3,6 \\
\hline 4. & Communicative & 2,8 & 3,8 & 2,9 & 3,1 \\
\hline 5. & Emotional value & 3,9 & 4,7 & 3,9 & 4,0 \\
\hline 6. & Emotional Regulatory Difficulties & 3,8 & 4,6 & 3,7 & 3,8 \\
\hline 7. & Ambition motivation & 2,6 & 3,2 & 2,5 & 2,6 \\
\hline 8. & Identification motives & 2,8 & 4,1 & 2,8 & 2,7 \\
\hline 9. & Pragmatic & 2,8 & 4,2 & 2,8 & 3,2 \\
\hline 10. Debt motivation & 3,1 & 4,5 & 3,1 & 3,4 \\
\hline 11. Integral indicator & 3,22 & 4,22 & 3,20 & 3,34 \\
\hline
\end{tabular}

Analysis of these data and their visual presentation (Fig. 4) allows us to draw a number of conclusions regarding the influence of specially created conditions for dialogical learning and psychological preparation on the indicators of motivation and ability to foreign languages.

It should be noted that neither the indicators of the level of ability in foreign languages nor the indicators of the level of motives for mastering a foreign language among Group B students have undergone significant changes. The exception is the indicators of pragmatic motivation and motivation of duty, which have shown their growth. There is also a slight increase in Emotional Regulatory Difficulties.

The indicators of motivation for language acquisition among Group A students revealed significant statistically significant changes: the most significant internal motives for optimal motivation, which include communicative, emotional-value, professional-creative and cognitive motivation, significantly increased in comparison with similar indicators at the diagnostic stage. This, in our opinion, is a consequence of changes in the motivation for mastering a foreign language and strengthening of the personal, dialogical orientation of the entire system of students' communication. 
As a result of experimental work on the organisation of dialogical teaching and psychological preparation of students on the principles of dialogical, personality-oriented creative foreign language communication, the hypothesis was confirmed, but in an even stronger form: the significant connection between the motivation of learning and the level of development of abilities for languages is fundamentally destroyed. In other words, in the conditions of student-centred learning, insufficient development of potential abilities for language (for example, not very good memory, deficiencies in thinking, insufficient flexibility of associations, etc.) ceases to be a factor that negatively affects the motivation of learning.

Figure 4. Diagnostic data of Group A and Group B based on the results of the experiment

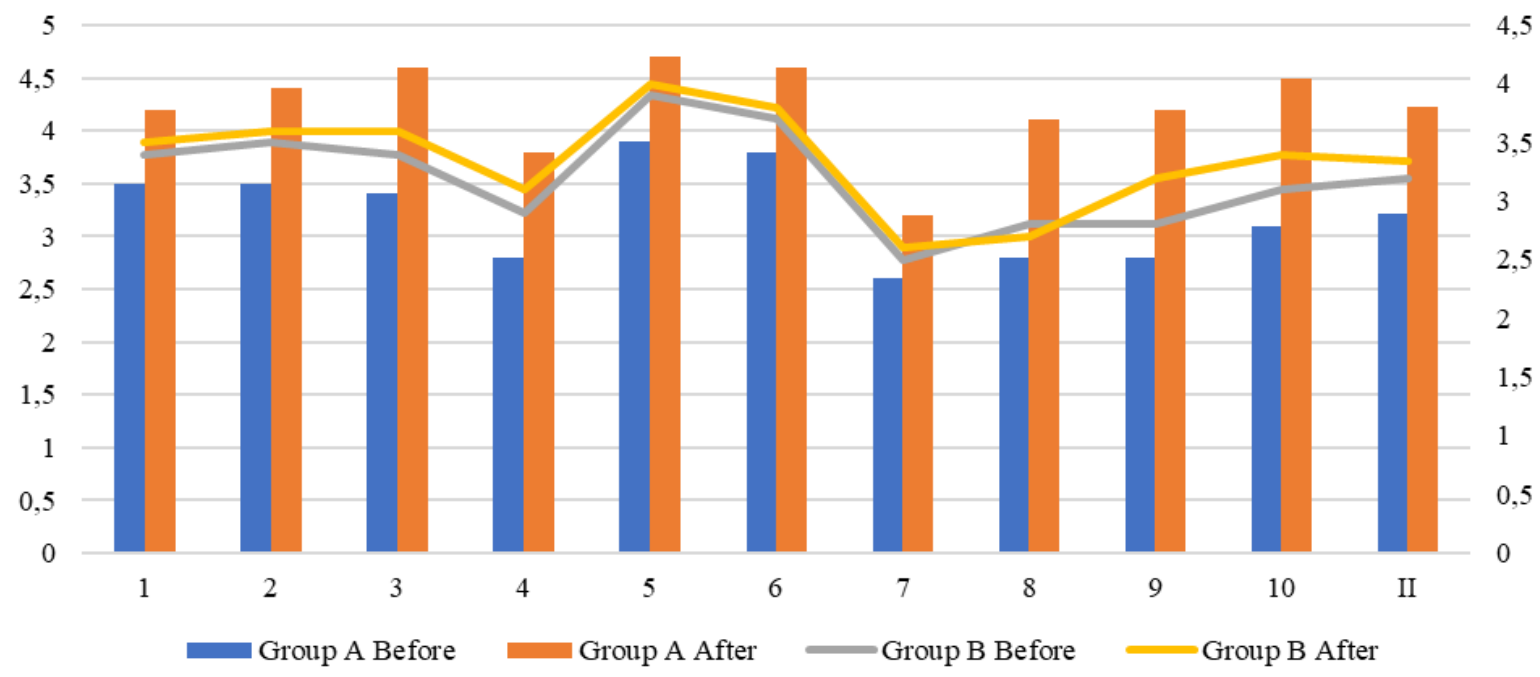

\section{Conclusion.}

Learning foreign languages is not only mastering foreign language competence, but also communicative flexibility, the ability to learn, emotional stability, as well as the ability to engage in the learning process psychologically. The effectiveness of such a multilateral process of mastering a foreign language is directly related to the motivation, psychological readiness of the student to learn and use a foreign language both in the classroom and in life situation, to believe in their abilities, not to be afraid to make mistakes and not to feel "embarrassed" in communicating in a foreign language, i.e. be able to overcome psychological barriers.

The systematic approach to the study and development of foreign language abilities involves considering them in a holistic set of personal properties of motivational, psychological, cognitive, emotional, volitional, communicative and emotional spheres of students' personality. When using dialogical communication in teaching a foreign language, not only optimal resolution of psychological difficulties of a different nature occurs, and successful mastering of a foreign language is ensured, but also a psychological readiness to overcome these difficulties is formed. Psychological support of educational work in foreign languages and the corresponding psychological preparation of students, aimed at overcoming learning difficulties, as the main one solves the problem of forming students' psychological readiness to understand and overcome these difficulties.

\section{References}

1. Ahmadian, M. (2018). Neurolinguistic Programming. In: Liontas, Jl and DelliCarpini, M, (eds.) The TESOL Encyclopedia of English Language Teaching. TESOL International Association \& Wiley, UK, DOI: 10.1002/9781118784235.eelt0171

2. Alkhazishvili, A. (1988). Osnovy ovladeniya ustnoy inostrannoy rech'yu (Fundamentals of mastering oral foreign speech), p.72-73 
3. Bancroft, W. (1976). Suggestology and Suggestopedia: The Theory of the Lozanov Method, 56p.

4. Beins, B. (2010). Barnum Effect, In book: Corsini Encyclopedia of Psychology. DOI: 10.1002/9780470479216.corpsy0108

5. Boyko V., Klitsenko O. (2002). Ocenka empatii lichnosti. [Assessment of empathy of the personality], St.-Petersburg: Publishing House Sudarinya, 286 p.

6. Friederici, A. (2011). The brain basis of language processing: from structure to function. Physiol Rev, 91 (4), pp. 1357-1392. DOI: 10.1152/physrev.00006.2011.

7. Genesee, F. (1989). Early bilingual development: One language or two? Journal of Child Language, 6, pp. 161-179.

8. Guryanova, L. et al. (2020). Machine Learning Methods and Models, Predictive Analytics and Applications. Machine Learning Methods and Models, Predictive Analytics and Applications 2020: Proceedings of the Workshop on the XII International Scientific Practical Conference Modern problems of social and economic systems modelling (MPSESM-W 2020), Kharkiv, Ukraine, June 25, 2020, Vol-2649, pp. 1-5.

9. Hulk, A. and Müller, N. (2000). Bilingual first language acquisition at the interface between syntax and pragmatics. Bilingualism: Language and Cognition, 3 (3), pp. 227-244.

10.Imedadze, N. (1978). Experimental and psychological studies of mastering a second language: Dissertation of the doctor of philological sciences, Tbilisi, $365 \mathrm{p}$.

11.Kitaygorodskaya, G. (1986). Methodology of Intensive Teaching Foreign Languages. Moscow: Nauka, 183 p.

12.Kosslyn, S., Osherson, D. (1996). An invitation to cognitive science. Cambridge, Mass.: MIT Press, The MIT Press; second edition, $363 \mathrm{p}$.

13.Lozanov, G. (1971). Suggestology = Sugestology. Sofia: Science and Art, 518 p.

14.Lozanov, G. (1973). Basics of Suggestology. Problems on Suggestology, pp. 55-70.

15.Newport, E. (1990). Maturational constraints on language learning. Cognitive Science, 14, pp. 1128. DOI:10.1207/s15516709cog1401_2

16.Paradis, J. and Genesee F. (1996). Syntactic Acquisition in Bilingual Children: Autonomous or Interdependent? Studies in Second Language Acquisition, 18, pp. 1-25.

17.Prokopenko, O. et al. (2020). Competence approach in future specialist skills development. International Journal of Management, 11(4), pp. 645-656. DOI: 10.34218/IJM.11.4.2020.062

18.Rosen, G. (2015). Barnum Effect, In book: The Encyclopedia of Clinical Psychology. DOI: 10.1002/9781118625392.wbecp482

19.Serratrice, L., Sorace, A. and Paoli S. (2004). Crosslinguistic influence at the syntax-pragmatics interface: Subjects and objects in English-Italian bilingual and monolingual acquisition. Bilingualism: Language and Cognition, 7 (3), pp. 183-205.

20.Steve, N. (1993). Kid's brain power. The Oregonian, Technology Review, 12-15-93, reprinted with permission from The Oregonian.

21.Tkachenko, V., Kuzior, A., \& Kwilinski, A. (2019). Introduction of Artificial Intelligence Tools into the Training Methods of Entrepreneurship Activities. Journal of Entrepreneurship Education, 22(6), 1-10. 